\title{
Peningkatan Derajat Kesehatan dengan Promosi Pola Hidup Bersih dan Sehat di Panti Asuhan Tebet, Jakarta Selatan
}

\author{
Putri Winda Lestari ${ }^{\mathrm{a}, 1, *}$, Partogi Michael Jordan ${ }^{\mathrm{b}, 2}$, Adham Herlambang Adi Chandra ${ }^{\mathrm{b}, 3}$, Bima \\ Badruzzaman $^{\mathrm{b}, 4}$, Sofi Latifah Lestari b,5 \\ a,b Universitas Binawan, Jl. Kalibata Raya 25-30 Jakarta Timur, Indonesia \\ ${ }^{1}$ winda@binawan.ac.id* \\ * corresponding author
}

\section{ARTICLE INFO}

\section{Keywords}

Sanitary Behavior;

PHBS;

Orphanage;

Education;

\section{ABSTRACT}

Sanitary behavior is a set of behaviors that are practiced based on awareness as a learning outcome, which makes a person, family, group, or community able to help themselves (independent) in the health sector and play an active role in realizing public health. The orphanage is a business institution to improve child welfare in alleviating child neglect. Environmental conditions in the orphanage are often ignored, causing the orphanage residents to suffer illness. Knowledge about sanitary behavior has also never been obtained by foster children because not many people care about this condition. The Tebet Orphanage is an orphanage located in South Jakarta, with most of the foster children at school-age. School-age children are an age group that is vulnerable to health problems. The initial survey shows that sanitary behavior has not been implemented in an orphanage properly. Therefore, it is necessary to educate about sanitary behavior. The target of this activity is to increase knowledge and understanding of sanitary behavior so that later foster children can implement clean and healthy lifestyles in their daily lives. The method used is to increase understanding or education about sanitary behavior. From the results of this activity, it can be seen that participants can understand the material presented. They are enthusiastic and active in the discussion. A similar program is needed so that community service activities are sustainable.

\section{PENDAHULUAN}

Salah satu modal pembangunan nasional adalah sumber daya manusia yang berkualitas yaitu sumber daya manusia yang sehat fisik, mental dan sosial serta memiliki produktifitas yang optimal. Untuk mewujudkan hal tersebut diperlukan upaya-upaya pemeliharaan dan peningkatan kesehatan secara terus menerus mulai sejak dalam kandungan, balita, usia sekolah sampai dengan usia lanjut (Nova, 2015).

Kesehatan merupakan hak asasi manusia dan salah satu unsur kesejahteraan yang harus diwujudkan sesuai dengan cita-cita bangsa Indonesia, sebagaimana dimaksud dalam Pancasila dan Undang-Undang Dasar Negara Republik Indonesia Tahun 1945. Berkaitan dengan hal itu, Undang-Undang Republik Indonesia Nomor 36 Tahun 2009 tentang Kesehatan menyatakan bahwa derajat kesehatan masyarakat yang setinggi-tingginya dicapai melalui penyelenggaraan pembangunan kesehatan (Kementrian Kesehatan RI, 2011).

Derajat kesehatan masyarakat dipengaruhi oleh kondisi lingkungan, perilaku masyarakat, pelayanan kesehatan dan genetika. Kalangan ilmuwan umumnya berpendapat bahwa determinan utama dari derajat kesehatan masyarakat tersebut selain lingkungan adalah perilaku masyarakat (Kementrian Kesehatan RI, 2011; Koem et al., 2015) 
Perilaku Hidup Bersih dan Sehat (PHBS) adalah sekumpulan perilaku yang dipraktikkan atas dasar kesadaran sebagai hasil pembelajaran, yang menjadikan seseorang, keluarga, kelompok atau masyarakat mampu menolong dirinya sendiri (mandiri) di bidang kesehatan dan berperan aktif dalam mewujudkan kesehatan masyarakat (Kementrian Kesehatan RI, 2011).

Penyakit yang akan muncul akibat rendahnya PHBS antara lain cacingan, diare (Fransisca et al., 2015), sakit gigi, sakit kulit, gizi buruk dan lain sebagainya yang pada akhirnya mengakibatkan rendahnya derajat kesehatan Indonesia dan rendahnya kualitas hidup sumber daya Indonesia (Koem et al., 2015).

Panti asuhan merupakan lembaga usaha untuk meningkatkan kesejahteraan anak dalam pengentasan ketelantaran anak. Kondisi lingkungan dan kesehatan anak di panti asuhan perlu diperhatikan, mengingat anak-anak memiliki hak yang sama untuk pemenuhan kesehatan dan kesejahteraannya Namun pada kenyataannya, kondisi lingkungan di panti asuhan kerap kali tidak diperhatikan, sehingga menyebabkan penghuni panti asuhan menderita sakit seperti jamur, kudis dan diare (Yuliyani et al., 2019). Pengetahuan tentang PHBS juga tidak pernah didapatkan oleh anak asuh karena tidak banyak yang peduli dengan kondisi ini (Kurniawan, 2017).

Panti Asuhan Tebet merupakan panti asuhan yang terdapat di Jakarta Selatan, dengan jumlah anak yang berada dalam pengawasan panti sebanyak 40 orang. Sebagian besar berada pada usia sekolah. Anak usia sekolah merupakan kelompok usia yang rentan terhadap masalah kesehatan. Survey awal menunjukkan bahwa belum terimplementasinya PHBS di panti asuhan secara baik. Oleh karena itu, perlu dilakukan edukasi tentang PHBS.

\section{Permasalahan Mitra}

Mitra pengabdian masyarakat ini adalah Panti Asuhan Tebet, Jakarta Selatan. Permasalahan yang dialami mitra adalah kurangnya penerapan perilaku hidup bersih dan sehat pada anak asuh.

\section{Solusi yang Ditawarkan}

Solusi yang ditawarkan adalah dengan melakukan promosi dan edukasi perilaku hidup bersih dan sehat (PHBS). Target dari kegiatan ini adalah untuk meningkatkan pengetahuan dan pemahaman mengenai Perilaku Hidup Bersih dan Sehat (PHBS) sehingga nantinya anak asuh dapat menerapkan pola hidup bersih dan sehat dalam kesehariannya.

\section{PELAKSAAAN DAN METODE}

Kegiatan pengabdian masyarakat ini dilakukan di Panti Asuhan Tebet: Yayasan Remaja Masa Depan berlokasi di Jalan Tebet Raya no. 69, RT.14/RW.1, Tebet Barat, Kec. Tebet, Kota Jakarta Selatan, Daerah Khusus Ibukota Jakarta pada bulan Juli 2019. Sasaran peserta kegiatan pengabdian masyarakat adalah sebanyak 20 anak asuh di Panti Asuhan Tebet dimana sebagian besar dari mereka adalan anak usia sekolah.

Metode yang akan dilakukan untuk memberikan solusi atas permasalahan tersebut adalah peningkatan pemahaman atau edukasi tentang Perilaku Hidup Bersih dan Sehat (PHBS). Dalam kegiatan ini dilakukan presentasi mengenai pengertian PHBS, indikator PHBS serta penyakit yang ditimbulkan akibat tidak menerapkan PHBS. Setelah kegiatan presentasi, dilakukan praktek kegiatan cuci tangan menggunakan sabun serta dilanjutkan sesi diskusi dan tanya jawab terkait materi pengabdian masyarakat.

Adapun langkah-langkah yang ditempuh dalam kegiatan pengabdian masyarakat ini mencakup beberapa tahap yaitu:

1. Tahap persiapan yaitu melakukan koordinasi internal, membuat proposal pengabdian masyarakat, pembagian job desk, membuat instrumen yang dibutuhkan (materi 
presentas dan daftar presensi), serta melakukan peizinan pada pengurus Panti Asuhan Tebet.

2. Tahap pelaksanaan yaitu kegiatan edukasi pada anak asuh di Panti Asuhan Tebet Kegiatan edukasi berupa penyampaian materi, diskusi dan tanya jawab.

3. Tahap akhir yaitu analisis feedback, pembuatan laporan, evaluasi kegiatan untuk melihat ketercapaian tujuan dan pembuatan luaran berupa artikel untuk dipublikasikan di jurnal pengabdian masyarakat.

\section{HASIL DAN PEMBAHASAN}

Terdapat sekitar 40 anak yang dikelola di Panti Asuhan Tebet. Sebanyak 20 anak asuh Panti Asuhan Tebet berpartisipasi dalam kegiatan pengabdian masyarakat ini dengan rata-rata pendidikan SD sederajat. Proses kegiatan pengabdian masyarakat yaitu tim pengabdian masyarakat terlebih dahulu memperkenalkan diri dan menyampaikan tujuan kegiatan pengabdian masyarakat. Kemudian dilanjutkan dengan kegiatan penyampaian materi edukasi yaitu terdiri dari materi tentang pengertian PHBS, indikator PHBS serta penyakit yang ditimbulkan akibat tidak menerapkan PHBS. Peserta pengabdian masyarakat terlihat antusias dan mendengarkan presentasi dengan seksama.

Setelah kegiatan presentasi, dilakukan praktek kegiatan cuci tangan menggunakan sabun. Berhubung peserta kegiatan ini rata-rata berpendidikan SD sederajat, maka untuk menarik minat peserta, praktek cuci tangan dilakukan sambil bernyanyi lagu cuci tangan 7 langkah. Hal ini bertujuan agar peserta lebih mudah memahami langkah cuci tangan yang baik dan benar.

Sesi diskusi dan tanya jawab dilakukan setelah materi disampaikan. Peserta kegiatan pengabdian masyarakat terlihat aktif bertanya dan menjawab pertanyaan yang disampaikan oleh tim pengabdian masyarakat. Dari sesi diskusi dan tanya jawab ini, terlihat peserta kegiatan pengabdian masyarakat memahami materi yang disampaikan. Harapannya, dengan meningkatnya pengetahuan peserta tentang PHBS, peserta dapat menerapkan pola hidup bersih dan sehat dalam kehidupan sehari-hari. Sehingga terjadi peningkatan derajat kesehatan anak asuh di Panti Asuhan Tebet.

Setelah dilakukan diskusi dan tanya jawab, tim pengabdian masyarakat melakukan games untuk menghibur peserta pengabdian masyarakat. Games berupa praktek cuci tangan dan tebak kata tentang PHBS. Kemudian dilanjutkan dengan pemberian souvenir oleh tim pengabdian masyarakat, peserta terlihat senang dan antusias.

Secara keseluruhan, kegiatan pengabdian masyarakat ini berjalan lancar. Berikut faktor pendorong kegiatan pengabdian masyarakat: kegiatan sudah dilakukan sesuai dengan tujuan serta sudah tepat sasaran, pengurus panti asuhan dan anak asuh menerima kedatangan tim pengabdian masyarakat dengan senang hati dan mereka berharap ada kelanjutan program yang akan dilakukan, waktu pelaksanaan program ini sudah tepat, yaitu disaat peserta sudah pulang mengaji serta semua pihak bersikap ramah, baik, dan cepat tanggap. Sedangkan faktor penghambat kegiatan ini adalah tidak semua anak asuh dapat ikut serta karena beberapa anak asuh sudah memiliki agenda kegiatan yang lain.

\section{SIMPULAN}

Secara keseluruhan, kegiatan pengabdian masyarakat berjalan lancar. Peserta kegiatan pengabdian masyarakat memahami materi yang disampaikan. Faktor pendorong kegiatan pengabdian masyarakat adalah kegiatan sudah dilakukan sesuai dengan tujuan serta sudah tepat sasaran, pengurus panti asuhan dan anak asuh menerima kedatangan tim pengabdian masyarakat dengan senang hati dan berharap ada kelanjutan program yang akan dilakukan, waktu pelaksanaan program ini sudah tepat, serta semua pihak bersikap ramah, baik, dan cepat tanggap. Sedangkan faktor penghambat kegiatan ini adalah tidak 
semua anak asuh dapat ikut serta karena beberapa anak asuh sudah memiliki agenda kegiatan yang lain.

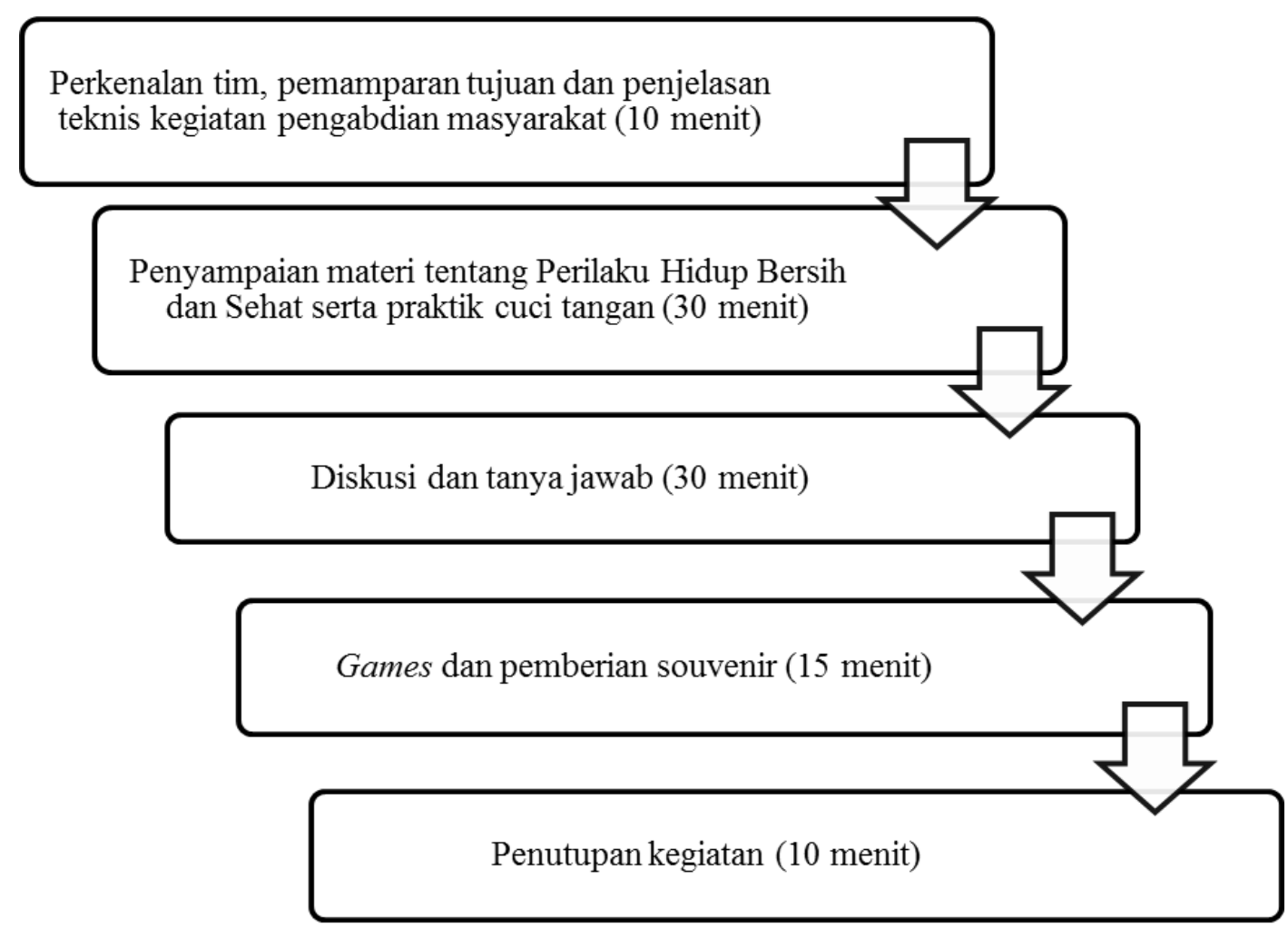

Gambar 1. Proses Pelaksanaan Kegiatan Pengabdian Masyarakat

\section{Foto-foto Kegiatan Pengabdian Masyarakat}

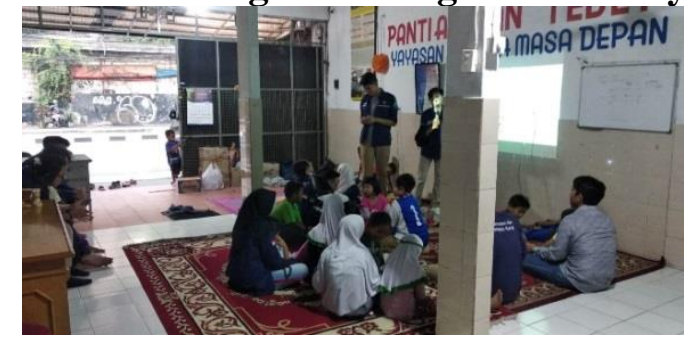

Gambar 2. Perkenalan tim pengabdian masyarakat

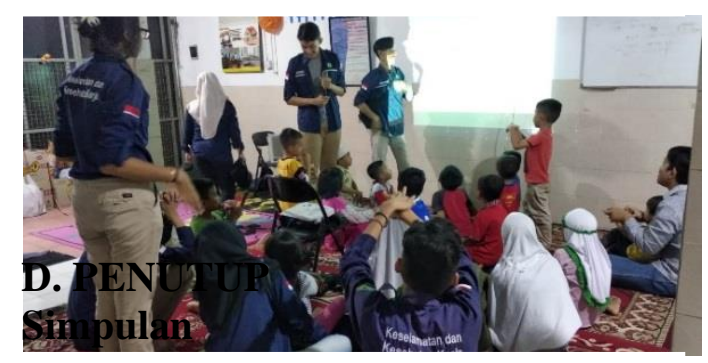

Gambar 3. Praktik cuci tangan

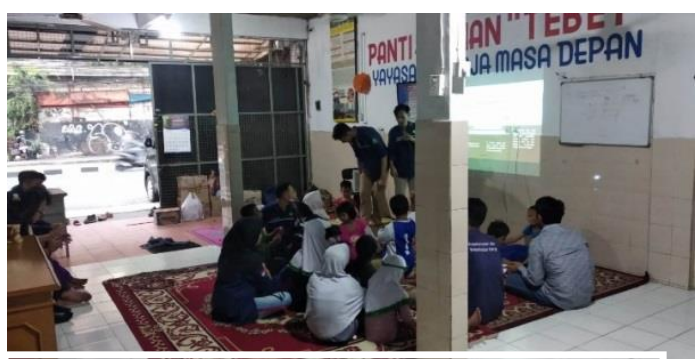

Gambar 3. Penyampaian materi

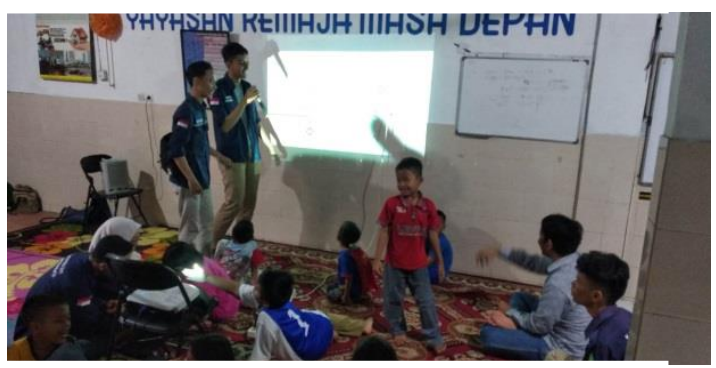

Gambar 4. Games

\section{Saran}

Berdasarkan hasil capaian kegiatan pengabdian masyarakat, maka saran kedepannya adalah perlu dilakukan program lain agar kegiatan pengabdian masyarakat ini dapat berkelanjutan. Misalnya program "Pemantauan Pola Hidup Bersih dan Sehat" yang 
dilakukan oleh pengurus panti kepada anak asuh atau program "Kakak PHBS" yang ditujukan kepada anak asuh yang berusia remaja untuk membimbing adik asuhnya agar dapat konsisten melakukan pola hidup bersih dan sehat.

\section{Ucapan Terima Kasih}

Dalam kegiatan pengabdian masyarakat ini, kami memperoleh banyak bantuan dari berbagai pihak. Terima kasih kepada LPPM Universitas Binawan atas dukungan dalam kegiatan ini, kepada pengurus Panti Asuhan Tebet yang sudah menjadi mitra kegiatan pengabdian masyarakat dan anak asuh Panti Asuhan Tebet yang telah bersedia menjadi peserta kegiatan pengabdian masyarakat.

\section{DAFTAR PUSTAKA}

Fransisca, R. O., Iriani, A. D., Mutiksa, F. A., Izati, S., \& Utami, R. K. (2015). Hubungan Infeksi Parasit Usus dengan Pengetahuan Perilaku Hidup Bersih Sehat pada Anak SD Bekasi, 2012. EJournal Kedokteran Indonesia, 3(1), 2-6. https://doi.org/10.23886/ejki.3.4802.16-20

Kementrian Kesehatan RI. (2011). Pedoman Pembinaan PHBS. Kementrian Kesehatan RI. https://doi.org/10.1017/CBO9781107415324.004

Koem, Z. A. ., Joseph, B., \& Sondakh, R. C. (2015). Hubungan Antara Pengetahuan dan Sikap dengan Perilaku HIdup Bersih dan Sehat (PHBS) pada Pelajar di SD Inpres Sukur Kecamatan Airmadidi Kabupaten Minahasa Utara. Pharmacon Jurnal Ilmiah Farmasi, 4(4), 290-294.

Kurniawan, H. (2017). Upaya peningkatan derajat kesehatan pada anak panti asuhan melalui edukasi hidup bersih dan sehat. Jurnal Pengabdian Masyarakat Ipteks, 3(1), 9-16.

Nova, B. (2015). Pelatihan Dokter Kecil dalam Upaya Meningkatkan Perilaku Hidup Bersih dan Sehat (PHBS) Siswa di SDN 2 Labuapi. Ganec Swara, 9(2), 128-132.

Yuliyani, V., Aryastuti, N., Nuryani, D. D., Sary, L., \& Shaharuddin. (2019). Perilaku Hidup Bersih dan Sehat di Panti Asuhan Al-Husna Bandar Lampung: Pengabdian Masyarakat Kerjasama dengan University Putera Malaysia. Jurnal Kreativitas Pengabdian Kepada Masyarakat, 2(1), 95-100. https://doi.org/10.1017/CBO9781107415324.004 